\title{
A Comparative Analysis of Different Future Weather Data for Building Energy Performance Simulation
}

\author{
Mamak P.Tootkaboni ${ }^{1, *(\mathbb{D})}$, Ilaria Ballarini ${ }^{1} \mathbb{D},{\text { Michele } \text { Zinzi }^{2}(\mathbb{D})}$ and Vincenzo Corrado $^{1}(\mathbb{D}$ \\ 1 Department of Energy, Politecnico di Torino, 10129 Turin, Italy; ilaria.ballarini@polito.it (I.B.); \\ vincenzo.corrado@polito.it (V.C.) \\ 2 ENEA, Via Anguillarese 301, 00123 Rome, Italy; michele.zinzi@enea.it \\ * Correspondence: mamak.ptootkaboni@polito.it
}

Citation: P.Tootkaboni, M.; Ballarini,

I.; Zinzi, M.; Corrado, V. A

Comparative Analysis of Different Future Weather Data for Building Energy Performance Simulation. Climate 2021, 9, 37. https://doi.org/ $10.3390 /$ cli9020037

Academic Editor: Steven McNulty

Received: 2 February 2021

Accepted: 19 February 2021

Published: 23 February 2021

Publisher's Note: MDPI stays neutral with regard to jurisdictional claims in published maps and institutional affiliations.

Copyright: (c) 2021 by the authors. Licensee MDPI, Basel, Switzerland. This article is an open access article distributed under the terms and conditions of the Creative Commons Attribution (CC BY) license (https:// creativecommons.org/licenses/by/ $4.0 /)$.

\begin{abstract}
The building energy performance pattern is predicted to be shifted in the future due to climate change. To analyze this phenomenon, there is an urgent need for reliable and robust future weather datasets. Several ways for estimating future climate projection and creating weather files exist. This paper attempts to comparatively analyze three tools for generating future weather datasets based on statistical downscaling (WeatherShift, Meteonorm, and CCWorldWeatherGen) with one based on dynamical downscaling (a future-typical meteorological year, created using a high-quality reginal climate model). Four weather datasets for the city of Rome are generated and applied to the energy simulation of a mono family house and an apartment block as representative building types of Italian residential building stock. The results show that morphed weather files have a relatively similar operation in predicting the future comfort and energy performance of the buildings. In addition, discrepancy between them and the dynamical downscaled weather file is revealed. The analysis shows that this comes not only from using different approaches for creating future weather datasets but also by the building type. Therefore, for finding climate resilient solutions for buildings, care should be taken in using different methods for developing future weather datasets, and regional and localized analysis becomes vital.
\end{abstract}

Keywords: climate change; future weather data; building energy performance; thermal comfort; statistical downscaling of climate models; dynamical downscaling of climate models

\section{Introduction}

There is an urgent need to address climate change as a primary global problem. According to the World Meteorological Organization (WMO) report on global climate, recent years have seen a continued increase in greenhouse gas concentration, global mean temperature, global sea level, and melting cryosphere [1]. The fifth assessment report (AR5) of the Intergovernmental Panel on Climate Change (IPCC) points out that if the emissions continue to rise, the global average temperature will be $2.6-4.8$ degrees Celsius $\left({ }^{\circ} \mathrm{C}\right)$ higher than the present by the end of the 21st century. Even if the greenhouse gas emissions stop immediately, the temperature increase will persist for centuries due to the effect of already present greenhouse gases in the atmosphere [2].

In addition to the changes in average temperature trend, extreme events intensify in frequency and magnitude; as an example, over the period 1880 to 2005, the frequency of heat waves in Europe has doubled, and longer heatwaves are more than $90 \%$ definite as the climate pattern has been disrupted [3]. The August 2003 heatwave was responsible for around 45,000 excess deaths across 12 European countries [4]. From 2015 to 2019, heatwaves were the deadliest meteorological hazard in many countries, particularly in Europe and North America [1], with an increase of mortality [5] and morbidity, especially for the elderly [6]. Consequences of these extremes included higher energy uses in buildings [5-7], infrastructure failures [8,9], and negative economic impacts [10,11]. 
Future climate scenarios affirm these trends, projecting different warming rates built upon a number of possible scenarios of future anthropogenic greenhouse gas emissions. The first set of scenarios was Emissions Scenarios (SRES), which were introduced in the IPCC 4th Special Report in 1996 [12]. Later, in 2014, the IPCC adopted a new series of scenarios called "Representative Concentration Pathways (RCPs)" that are established using hypotheses about economic growth, choices of technology, and land use [2]. RCPs are identified by their associated warming effect (radiative forcing, which is measured in units of watts per meter squared) in the year 2100. Radiative forcing is a direct measure of the amount Earth's energy imbalance. The four RCPs (RCP2.6, RCP4.5, RCP6.0, and $\mathrm{RCP} 8.5$ ) span a range of assumptions about future controls on greenhouse gas (and other) emissions. The lowest RCP represents a very aggressive Green House Gases (GHG) mitigation scenario aimed at limiting global warming to about $2{ }^{\circ} \mathrm{C}$, while the highest $\mathrm{RCP}$ corresponds to minimal effort to reduce GHG emissions this century. The RCP 8.5 assumes that atmospheric concentrations of $\mathrm{CO}_{2}$ are three to four times higher than pre-industrial levels by 2100 [2].

Insights from these future scenarios demonstrate the urgent need for emission reduction in a wide range of relevant sectors. Among these sectors, the building stock is one of the main greenhouse gas emitters, which in the European Union accounts for $50 \%$ of the $\mathrm{CO}_{2}$ emissions [13]. In addition, buildings will be also subjected to a warmer climate due to their long lifespan. The existing body of research on the effect of climate change on the future performance of buildings predicts that there will be a paradigm shift in building energy performance. Unsurprisingly, a drastic rise in cooling energy use and a moderate decrease in heating energy use is predicted [14-16]. Recently, in the study of Soutullo et al. [17], for two reference buildings in Madrid, the annual heating and cooling requirements were shown to be around $22 \%$ lower and higher, respectively, just by considering the effect of climate change in the last decade. In addition, many studies revealed that this trend may happen even in energy efficient dwellings. Da Guarda et al. [18] analyzed the vulnerability of a zero-energy building (ZEB) to the impact of climate change in 2020 (2011 to 2040), 2050 (2041 to 2070), and 2080 (2071 to 2100). Results showed that due to the increase in cooling energy consumption, there will be a power generation gap up to $40.2 \%$ for the 2080 period. In addition, the climate change impact magnitude is not equal for different scenarios, case studies, and regions. Zhai and Helman [19] studied a campus building stock energy prediction, using four future climate models, which are representative of 56 model scenarios for seven climate zones in US. The results demonstrated that cooling energy increases variously $(5 \%, 28 \%, 20 \%$, and $52 \%)$ for different scenarios. In another study, Chai et al. [20] analyzed the life cycle of a net zero energy building in typical climate regions of China. It was concluded that among the different climate regions, the impact of climate change on energy balance and thermal comfort varies significantly. So, in a changing climate, it becomes necessary to prepare buildings for the future at the regional scale, considering different scenarios, to avoid problems such as overheating and power outage, which brings health risks for the occupants.

To investigate the future performance of a building in the context of climate change, building energy simulation (BES) is a vital support tool. BES needs a robust weather dataset that defines the external boundary conditions the building will face during its lifetime. Typically, a representative year of hourly weather data is required to represent the typical regional climate condition and to define the dynamic energy behavior of the building. Several methodologies have been developed to create this one-year climate data from historical climate records [21]. The most commonly used methodology is the Typical meteorological year (TMY), which was introduced in 1978 [22]. TMY is a fictive year constructed of twelve representative typical months [23]. Representative months are selected by comparing the distribution of each month with the long-term distribution of that month for the available climate dataset (the Finkelstein-Schafer statistics) [24]. The analysis of the present climate is based on the observation of climate variables and the application of statistical methods for understanding the current trends. On the other 
hand, the analysis of future climate is based on future scenarios and the projections of climate models.

Future scenarios are the input data used to provide initial conditions for General Circulation Models or Global Climate Models (GCMs), which are models for forecasting climate change. GCMs provide climate information on the global scale with a typical spatial resolution of 150-600 $\mathrm{km}^{2}$ [2]. Consequently, if they are used for building energy simulation, the climate change effect and related weather extremes at the local level will not be considered. In this case, the GCMs should be downscaled to applicable spatial (less than $100 \mathrm{~km}^{2}$ ) and temporal resolution (less than monthly value). There are two main approaches to downscale GCMs: dynamical and statistical downscaling. Several studies compared different methodologies that use these approaches for the generation of future weather data. Jentsch et al. indicate that weather variability is not generated in the statistically downscaled weather dataset and this approach includes the effect of climate change independently between the variables [25]. On the other hand, Dias et al. point out that the statistical downscaling approach has the advantage of reducing the computational time so that various climate change scenarios can be applied [26], besides providing enough information to study the performance of the building [27]. In light of these studies, there is still a need to deeply analyze different methodologies for future weather data generation.

This study aims to contribute to evaluating the suitability and robustness of different future weather data for analyzing the future performance of reference buildings both in terms of thermal comfort and energy performance. It represents a comparative study of four future weather datasets. Three of them were produced using common weather generator tools available today (WeatherShift, Meteonorm, and CCWorldWeatherGen), which apply statistical downscaling. The other one is a TMY created using a high-quality regional climate models database (from Euro-Coordinated Regional Climate Downscaling Experiment (CORDEX)) that applies the dynamical downscaling. The study investigates the impact of each type of these future weather data in the building energy performance and thermal comfort predictions. It evaluates the heating and cooling demand, the overall energy performance in the presence of heating and cooling systems with continuous operation, and the overheating risk in a free-floating regime of two building types, which are representative of the existing residential building stock in Italy, using the EnergyPlus simulation engine [28]. The analysis was carried out for Rome, as it is one of the representative cities of Mediterranean hot summer climates according to Köppen classification [29]. Representative Concentration Pathways 8.5 (business as usual) [2] have been applied in this study for the mid-century period from 2040 to 2060. This period was used for the analysis, since GCMs uncertainties due to internal climate variability, climate model, and future scenarios increase significantly over time [30,31].

The next section provides a short background on downscaling of the global climate models for generating future weather files for BES. The following sections present the methods and case studies used in this study, the results and discussion, and the conclusion.

\section{Review of GCMs Downscaling Methods}

Global climate models are complicated numerical models that simulate the state and evolution of the atmosphere, including the atmospheric circulation and energy exchanges in terms of radiation, heat, and moisture. They simulate the processes related to cloud formation and precipitation and take into account the interaction with the ocean and the land [32]. To check if GCMs can simulate the evolution of the climate systems, they are validated against past climate conditions [33]. After verification and validation, GCMs are set to run by forcing greenhouse gas concentration scenarios as an initial condition. GCMs results have global or continental scale spatial resolution and long temporal resolution such as seasonal or annual periods. Due to these coarse resolutions, the direct use of GCMs outputs for building performance assessment is not possible. As previously mentioned, to reach local climate and applicable temporal resolution, downscaling of the GCMs is 
required. Statistical downscaling and dynamical downscaling are two main approaches; they are presented in Sections 2.1 and 2.2.

\subsection{Statistical Downscaling}

Statistical downscaling develops and applies statistical relationships between regional or local climate variables and large-scale climate data using deterministic or stochastic approaches [27]. This downscaling approach is a computationally less demanding alternative that facilitates achieving various sets of results. The simplicity of this method-in comparison with dynamical downscaling - persuades many researchers to favor it. This method is mostly applied to GCM projections, while it may also be applied to RCM output as being a better representative for the local climate [34]. In the two following sub-sections, major approaches for applying statistical downscaling are explained in more detail.

\subsubsection{Stochastic Weather Generation}

Stochastic weather generators are among statistical models, which fill in missing data and enable the production of long synthetic weather series indefinitely. This becomes possible through simulating major properties of observed meteorological records, including daily means, variances and covariances, frequencies, extremes, etc. [35]. These models rely on statistical analysis of recorded climate data in which a few independent weather variables-such as solar radiation-are adequate to derive all other relevant variables. The stochastic weather generation method has the advantage of enabling the integration of the distribution used for the climate change signal. In addition, it is accountable for potential changes in weather patterns and climate variability [32]. However, what appears to be a limitation of this method is the need for a large amount of data to train the model, since distributions for generating future data are based on the baseline data given to the model [35]. The well-known tool that uses this method is Meteonorm. More details about this software and the way it becomes applied in this study will be explained in Section 3.1.1.

\subsubsection{Time Series Adjustment: Morphing}

Morphing is the most common statistical downscaling method for the adjustment of time series toward the future. This method was firstly presented by Belcher et al. in 2005, assuming the current weather data as baseline [35]. In order to transform this baseline to a future time series, monthly climate change signals given by a GCM or Regional Climate Model (RCM) are used. There are three ways to morph data-shifting, scaling, or a combination of them-depending on the climate variable and expression of the climate change signal (absolute, relative):

- The Shift is applied when absolute monthly mean change $\left(\Delta x_{m}\right)$ derived from a GCM or RCM is predicted for a given variable $\left(x_{0}\right)$ such as atmospheric pressure, for the month $m$, according to Equation (1):

$$
x_{m}=x_{0}+\Delta x_{m} .
$$

- The Stretch is applied when a relative monthly mean change $\left(\alpha_{m}\right)$ derived from a GCM or RCM is predicted for a given variable $\left(x_{0}\right)$ such as wind speed, for the month $\mathrm{m}$, according to Equation (2):

$$
x_{m}=\alpha_{m} \cdot x_{0} .
$$

- The combination of Shift and Stretch is applied when both absolute and relative monthly mean changes derived from a GCM or RCM are predicted for a given variable $\left(x_{0}\right)$ such as dry-bulb temperature, for the month $\mathrm{m}$, according to Equation (3):

$$
x_{m}=x_{0}+\Delta x_{m}+\alpha_{m}\left(x_{0}-x_{0, m}\right)
$$

where $x_{0, m}$ is the variable $x_{0}$ average over month $m$ for all the considered averaging years of future data provided by the climate models. 
CCWorldWeatherGen and WeatherShift are two available tools that use the morphing method to create future weather data. More details about these tools and their application in this study will be explained in Sections 3.1.2 and 3.1.3.

\subsection{Dynamical Downscaling}

Dynamical downscaling uses a nesting strategy to obtain climate information at a resolution of $2.5-100 \mathrm{~km}^{2}$. To this aim, a Regional Climate Model (RCM) is used to derive local or regional climate information. This method simulates "atmospheric and land surface processes, while accounting for high resolution topographical data, land-sea contrasts, surface characteristics, and other components of the Earth-system" [36]. The climate information generated by RCMs has much finer spatial resolution compared to GCMs. This allows RCMs to better represent the spatial and temporal variability of local climate and guarantee physically consistent datasets [37]. However, a large amount of computational power and storage for data creation is one of the limitations of this method. Furthermore, the accuracy of the relevant GCM determines the overall quality of the output. In order to evaluate such uncertainties, different GCM-RCM pairings are combined, and a series of simulations are performed. ENSEMBLES [38] and EURO-CORDEX [39] projects are two of such efforts.

EURO-CORDEX — as the main reference framework for regional downscaling researchaims to facilitate the process of knowledge exchange and communication. Many sectorse.g., building sector, agriculture, heat and fire risk, and air quality - utilize EURO-CORDEX, since it provides a consistent database of downscaled multi-year projections for various regions all over the world [40]. In addition, by providing a better understanding of the regional and local climate and its associated uncertainties, EURO-CORDEX evaluates and enhances different RCMs. CORDEX includes a large RCM database, and it is updated by new climate data from available domains all over the globe [41]. For European countries, the grid resolution provided by EURO-CORDEX projections equals $12.5 \mathrm{~km}$. For Middle East and North Africa, this quantity is $25 \mathrm{~km}$, while the rest of the world has the grid resolution of $50 \mathrm{~km}$. The time scales-on which the data in the multi-layer format are available-include monthly, daily, every six hours, every three hours, and hourly during the historical period from 1976 to 2005 and for the future period, from 2006 to 2100. The data are available either for RCP 4.5 or RCP 8.5 scenarios, depending on the model [42]. Although most of the available data on the platform are not bias-adjusted, a number of bias-adjusted data are available for some specific models and climate variables. In this study, the hydrostatic version of the regional model REMO-2015 (from $0.11^{\circ}$ resolution of the CORDEX European domain), developed by the Max Planck Institute for Meteorology in Hamburg, Germany and currently maintained at the Climate Service Center Germany (GERICS) in Hamburg is used $[43,44]$. The utilization of this model in creating future TMY for this study is discussed in Section 3.1.4.

\section{Materials and Methods}

\subsection{Describing Future Weather Data Generation for Rome}

Four future weather datasets to be analyzed in this work were generated for Rome, using Meteonorm, CCWorldWeatherGen, and WeatherShift weather generator tools, and one RCM (GERICS-REMO-2015) from the EURO-CORDEX project. The weather datasets were developed for the mid-century period from 2040 to 2060. In the study of Hawkins and Sutton, this period (around 2050) is indicated as the period in which temperature predictions will be best in comparison with other periods during the century. Uncertainties of GCMs due to the internal climate variability, climate model, and future scenarios increase significantly over time [30,31]. The following sub-sections describe the applied methodology in detail. 


\subsubsection{Meteonorm}

By integrating the climate database with spatial interpolation of the principal weather variables and a stochastic weather generator, Meteonorm generates hourly weather data for any site in the world [45]. These data can be used as an input for building performance simulation. Weather variables such as global irradiance on a horizontal plane at the ground level, dry-bulb temperature, dew-point temperature, and wind speed are provided by Meteonorm. This tool can be also used for climate change studies. GCMs under the IPCC fourth assessment report (AR4) [46] are used in this tool to generate future weather data for different emission scenarios (B1, A1B, and A2), with 10-year intervals from 2010 until 2100 [47]. The Meteonorm version 7.2 was used in this study to generate a typical meteorological year of 2050 for the A2 emission scenario (pessimist scenarios) for the city of Rome.

\subsubsection{CCWorldWeatherGen}

The CCWorldWeatherGen is a Microsoft ${ }^{\circledR}$ Excel based tool developed by the Sustainable Energy Research Group of Southampton University [25]. It uses the Morphing methodology to create future weather datasets in Energy Plus Weather (EPW) format for different locations all over the world. The output data of UK Met-office, the Hadley Center Coupled Model 3 (HadCM3) [48] global climate model, forced with IPCC A2 emission scenarios is used in this tool. The HadCM3 climate model was chosen since by the timein comparison with 29 other climate models-this model was the only one that had all necessary climate variables for the morphing procedure [49]. What HadCM3 provides as input for the Morphing procedure in CCWorldWeatherGen is the monthly value of relative changes regarding the period of 1961-1990. The Excel tool superimposes this input on the weather variables of the baseline weather data stored in an EPW file. The tool generates future weather data sets for 3 time slices: 2001-2040 (referred as '2020s'), 2041-2070 (referred as '2050s'), and 2071-2100 (referred as '2080s'). Being a free online tool is an advantage that makes it widely used. However, due to possible differences in the reference time frame between HadCM3 and the EPW data, inaccuracy in the outputs of the tool may occur [50]. In this study, the International Weather for Energy Calculation (IWEC) TMY file of Rome- downloaded from the Energy Plus database-was used to be morphed for the time slice of 2050s.

\subsubsection{WeatherShift}

The WeatherShift TM tool was developed upon morphing methodology by Arup and Argos Analytics for creating future weather data [51]. "The tool blends 14 of the more recently simulated GCMs (BCC-CSM1.1, BCC-CSM1.1(m), CanESM2, CSIRO- Mk3.6.0, GFDL-CM3, GFDL-ESM2G, GFDL-ESM2M, GISS-E2-H, GISS-E2-R, HadGEM2-ES, IPSLCM5A-LR, IPSL-CM5A-MR, IPSL-CM5B-LR, NorESM1-M) into cumulative distribution functions (CDF) [52]. It is based on RCP 4.5 and 8.5 emission scenarios of the IPCC fifth assessment report. Creating CDFs allows a percentile distribution (called warming percentile factor) and "smooths out" the inter-modal uncertainty and stochastic climate behavior [53]. The tool produces future weather data for time periods of 20 years starting from 2011 and ending in 2100. The morphing method in this tool is applied in 8 climate variables of the reference TMY: the mean, maximum, and minimum daily temperature, relative humidity, daily total solar irradiance, wind speed, atmospheric pressure, and precipitation. The future projections are relative to the baseline period of 1976-2005. In this study, the 50th percentile and the RCP 8.5 emission scenarios were selected to set the tool for generating future weather datasets of Rome for the period of 2041-2060. The IWEC-TMY was the baseline for this procedure.

\subsubsection{TMY out of GERICS-REMO-2015}

As mentioned earlier, the GERICS-REMO-2015 regional climate model was used in this study to apply the dynamical downscaling method. The data for this model 
were downloaded from the EURO-CORDEX entry point through the Earth System Grid Federation (ESGF) for the Europe domain on a $0.11^{\circ}$ grid in rotative coordinates (equivalent to a $12.5 \mathrm{~km}$ grid). These data are available in the NetCDF4 format, which is a file format for storing multidimensional scientific data. The extraction of the data for our case study (city of Rome) was performed through the Cordex Data Extractor software [54] that allows finding the closest data point on the grid to the desired latitude and longitude. The RCP 8.5 scenario was adapted to extract these data for the 2041-2060 period. The driving model considered in this study is MPI-M-MPI-ESM-LR, which is well supported according to the IPCC report on the evaluation of climate models [55].

In order to create a future typical meteorological year (F-TMY) for the city of Rome out of the 20 years of extracted data, the methodology of standard EN ISO 15927-4 [56] was used. This international standard covers the selection of appropriate meteorological data for the assessment of the long-term mean energy use for heating and cooling. TMY is constructed from 12 representative months (Best Months) from multi-year records. The selection of Best Months is done by comparing the cumulative distribution function of the single and reference years through the Finkelstein-Schafer (FS) statistics [24]. This method was used in this study since the criteria for selecting the Best Month is not merely limited to dry-bulb air temperature; it also takes the global solar irradiance, relative humidity, and wind speed into account.

\subsection{Energy Performance and Thermal Comfort Assessment}

The building energy performance was assessed by means of a detailed dynamic simulation model using EnergyPlus (version 9.0) with an hourly time-step. The results are discussed in terms of annual thermal energy need for space heating and space cooling $\left(E P_{\mathrm{H} / \mathrm{C}, \text { nd }}\right)$ and electrical energy demand per unit of area $\left(E_{\mathrm{el}} / A_{\mathrm{f}}\right)$. The latest indicator $\left(E_{\mathrm{el}} / A_{\mathrm{f}}\right)$ was calculated according to Equation (4):

$$
E_{\mathrm{el}} / A_{\mathrm{f}}=\frac{E P_{\mathrm{H}, \mathrm{nd}}}{\eta_{\mathrm{H}, \mathrm{u}} \cdot \eta_{\mathrm{H}, \mathrm{g}}}+\frac{E P_{\mathrm{C}, \mathrm{nd}}}{\eta_{\mathrm{C}, \mathrm{u}} \cdot \eta_{\mathrm{C}, \mathrm{g}}}
$$

where $E P_{\mathrm{H} / \mathrm{C}, \text { nd }}$ is the annual thermal energy need for space heating/cooling, $\eta_{\mathrm{H} / \mathrm{C}, \mathrm{u}}$ is the mean seasonal efficiency of the heating/cooling utilization (including emission, control, and distribution) subsystems, and $\eta_{\mathrm{H} / \mathrm{C}, \mathrm{g}}$ is the mean seasonal efficiency of the heating/cooling generation subsystem.

The reference mean seasonal efficiency values of the utilization subsystems were assumed in compliance with the Italian Interministerial Decree of June 26th, 2015 [57]. As a reversible heat pump has been selected as a generation subsystem type to carry out the analysis, a future value of the mean seasonal generation efficiency was adopted to take into account the increase of the ambient temperature due to climate change. The generation efficiency was calculated assuming proportionality between the coefficient of performance $(C O P)$ and its maximum theoretical efficiency over different temperatures, as in Equation (5):

$$
\eta_{\mathrm{H}, \mathrm{g}} \sim \frac{\sum_{\text {heating season }} \Phi_{\mathrm{H}}}{\sum_{\text {heating season }}\left(\Phi_{\mathrm{H}} \cdot \frac{T_{\text {cond,out }}}{T_{\text {cond,out }}-T_{\text {evap in }}}\right)}
$$

where $\Phi_{\mathrm{H}}$ is the thermal energy load for heating, $T_{\text {cond,out }}$ is the condenser outlet temperature (hot water), and $T_{\text {evap,in }}$ is the evaporator inlet air temperature.

In the same way, proportionality between the energy-efficiency ratio $(E E R)$ and its maximum theoretical efficiency over different temperatures has been assumed, as in Equation (6):

$$
\eta_{\mathrm{C}, \mathrm{g}} \sim \frac{\sum_{\text {cooling season }} \Phi_{\mathrm{C}}}{\sum_{\text {cooling season }}\left(\Phi_{\mathrm{C}} \cdot \frac{T_{\text {evap out }}}{T_{\text {cond,in }}-T_{\text {evap }, \text { out }}}\right)}
$$

where $\Phi_{C}$ is the thermal energy load for cooling, $T_{\text {evap,out }}$ is the evaporator outlet temperature (chilled water), and $T_{\text {cond,in }}$ is the condenser inlet air temperature. 
The thermal comfort was assessed in accordance with the EN 16798-1 standard [58]. The adaptive comfort model was adopted to predict how the pattern of outside weather conditions affect the indoor thermal sensation of the user in free-floating condition. In this model, the optimal operative temperature $\left(\theta_{0, c}\right.$, in $\left.{ }^{\circ} \mathrm{C}\right)$ is calculated as in Equation (7):

$$
\theta_{o, c}=0.33 \cdot \theta_{r, m}+18.8
$$

where $\theta_{r, m}$ is the outdoor running mean temperature, which is defined as an exponential running mean of the outdoor air temperature.

In this research, a medium level of occupant expectation (i.e., second category of indoor environmental quality, as defined in [58]) was applied, in which the range of comfort is between $\theta_{0, c}+3{ }^{\circ} \mathrm{C}$ (highest limit) and $\theta_{0, c}-4{ }^{\circ} \mathrm{C}$ (lowest limit). In addition, the hours of exceedance $(H E)$ were calculated as an indicator to quantify indoor overheating. The $H E$ indicator is equal to the number of hours during the cooling period in which the operative temperature of the zone is greater than the upper limit temperature of the thermal comfort range.

\subsection{Definition of Case Studies}

Representative buildings of the Italian residential building stock were used to carry out the comparison between the future weather datasets. The buildings have been selected from the Italian Building Typology Matrix developed in the Intelligent Energy EuropeTypology Approach for Building Stock Energy Assessment (IEE-TABULA) research project [59], which aimed at creating a harmonized definition of the residential building typology at the European level. The two selected building types (Figure 1) belong to the categories of single-family house (SFH) and apartment block (AB), respectively, and both were built in the construction period 1946-1960. The two building sizes present a significantly different shape factor- $0.73 \mathrm{~m}^{-1}$ for the $\mathrm{SFH}$ and $0.46 \mathrm{~m}^{-1}$ for the $\mathrm{AB}$ - and window-to-wall ratio: 0.09 for the SFH and 0.23 for the $\mathrm{AB}$.

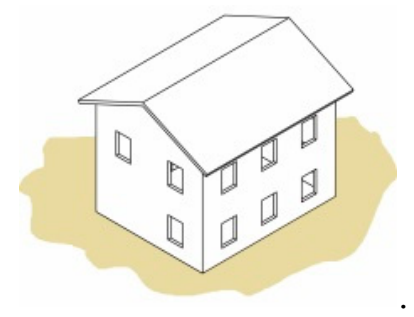

(a)

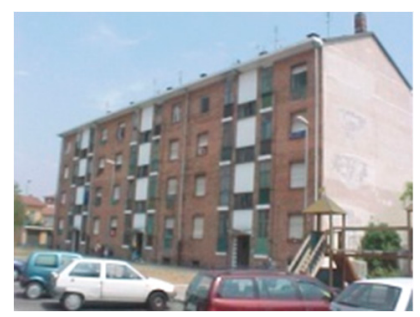

(b)

Figure 1. Italian residential building-types of the construction period 1946-1960, according to the IEE-TABULA project: single-family house (a) and apartment block (b).

The buildings have uninsulated envelope components, as the construction period predates the first Italian law on energy savings issued in 1976. The opaque external wall is a solid brick masonry $\left(U=1.48 \mathrm{~W} \cdot \mathrm{m}^{-2} \mathrm{~K}^{-1}\right.$ the $S F H$, and $U=1.15 \mathrm{~W} \cdot \mathrm{m}^{-2} \mathrm{~K}^{-1}$ the $A B$ ), while the horizontal envelope components are reinforced brick-concrete slabs $\left(U=1.65 \mathrm{~W} \cdot \mathrm{m}^{-2} \mathrm{~K}^{-1}\right)$. The transparent envelope components are single glazing $\left(\mathrm{g}_{\mathrm{gl}, \mathrm{n}}=0.85\right)$ and wood-frame windows $\left(U=4.90 \mathrm{~W} \cdot \mathrm{m}^{-2} \mathrm{~K}^{-1}\right)$ with exterior wooden Venetian blinds $(g \mathrm{gl}+\mathrm{sh}=0.35)$.

A reference technical building system was assumed for the case studies in the present work. It consists in an electrical reversible air-to-water heat pump coupled with fan coils.

The energy performance of the buildings was assessed assuming a standard user behavior for the quantification of the internal heat gains and the airflow rates by natural ventilation [60]. A continuous operation of the heating and cooling systems was set, considering $20{ }^{\circ} \mathrm{C}$ and $26{ }^{\circ} \mathrm{C}$ temperature set points, respectively. The heating season covers the period between October 15th and April 15th as fixed by the Italian energy 
regulations. The availability of the cooling system was assumed in the remaining part of the year (from April 16th to October 14th).

\section{Results and Discussion}

The aim of this research is to analyze different types of future weather datasets by comparing their relative impact on building energy performance predictions. In the first set of results, boxplots of the outdoor dry-bulb temperature (a) and the global horizontal solar irradiance during daily hours (b), which are the weather key variables in building energy simulation, are plotted (Figure 2). Boxplots show a pattern of increase in both variables due to climate change. All future weather files show almost similar mean values higher than the present weather file. Nevertheless, F-TMY - which is derived from a dynamical downscaling method-shows lower dispersion compared to other future files (statistically downscaling methods).

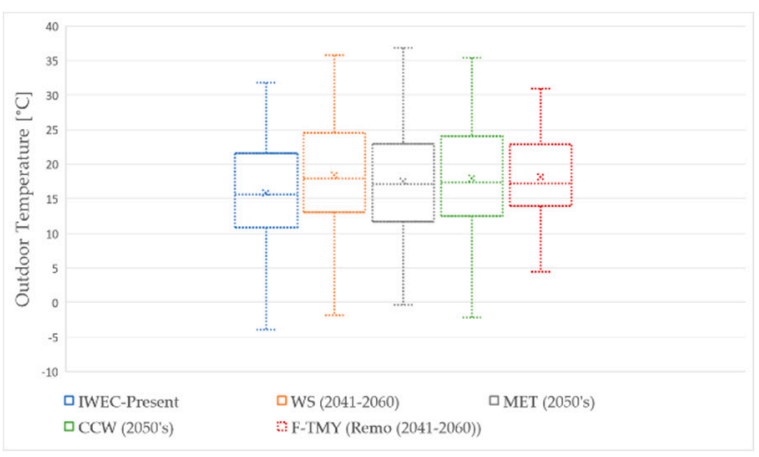

(a)

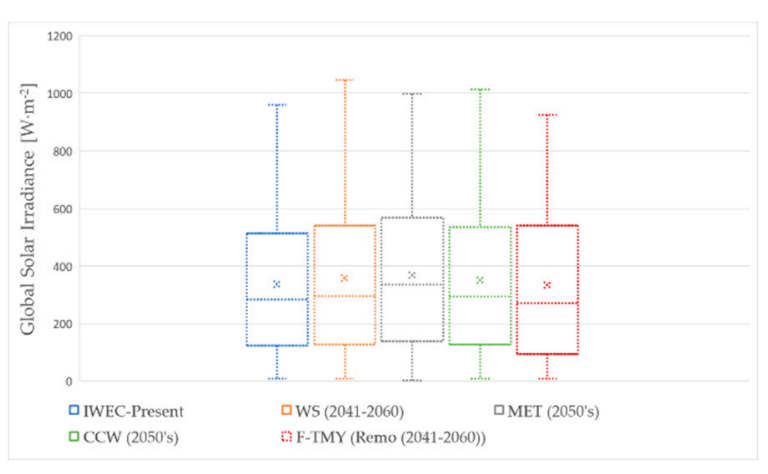

(b)

Figure 2. Boxplots of the outdoor dry-bulb temperature (a) and the global horizontal solar irradiance during daily hours (b) for IWEC (Present), Weathershift (WS), Meteonorm (MET), CCWorldWeatehr-Gen (CCW), and F-TMY. All future weather files are for 2050s considering Representative Concentration Pathway (RCP) 8.5.

Below, Figure 3 presents net thermal energy needs for heating and cooling normalized by the conditioned floor area for a mono family house (a) and apartment block (b) for present and different future weather data to assess the building energy performance of the case studies. The heating energy demand for the mono family house (MFH) dominates over cooling demand. In addition, MFH has also higher energy demand for heating compared to the apartment block (AB). This is due to the higher shape factor $(\mathrm{S} / \mathrm{V})$ ratio, which entails that heat transfer by transmission is the most relevant term of the energy balance, and outdoor temperature is the main driving force. Consequently, the decrease of $E P_{\mathrm{H}, \text { nd }}$ in the future prevails over the increase of $E P_{C, n d}$. On the opposite, the $A B$ shows closer values of $E P_{\mathrm{H}, \text { nd }}$ and $E P_{\mathrm{C}, \text { nd }}$. It appears that the heating need is slightly dominant in the present, but it will be overtaken by cooling in the future. For all future weather data except F-TMY, the relative change of $E P_{\mathrm{H}, \text { nd }}$ is in the range of $30 \%$ to $34 \%$ for both buildings, while the relative change of $E P_{\mathrm{C}, \text { nd }}$ is above $160 \%$ for $\mathrm{MFH}$ and above $100 \%$ for $\mathrm{AB}$. This unevenness in relative variation is mainly related to the different magnitude of the present energy need. As regards F-TMY, lower values of $E P_{\mathrm{H}, \mathrm{nd}}$ and $E P_{\mathrm{C}, \text { nd }}$ are shown compared to the other future weather data, meaning that $E P_{\mathrm{H}, \text { nd }}$ will decrease more and $E P_{\mathrm{C}, \text { nd }}$ will increase less. This trend is strictly dependent on the lower dispersion of temperature values for F-TMY compared to the other future weather datasets. Comparing the four sets of weather data, Weathershift (WS), Meteonorm (MET), and CCWorldWeatehrGen $(\mathrm{CCW})$ show almost similar variations in $E P_{\mathrm{H}, \text { nd }}$ and $E P_{\mathrm{C} \text {,nd }}$, while the F-TMY presents a significantly different variations in the two indicated parameters. This comes from the fact that WS, MET, and CCW are all statistically downscaled weather datasets, and F-TMY is a dynamically downscaled weather dataset. 


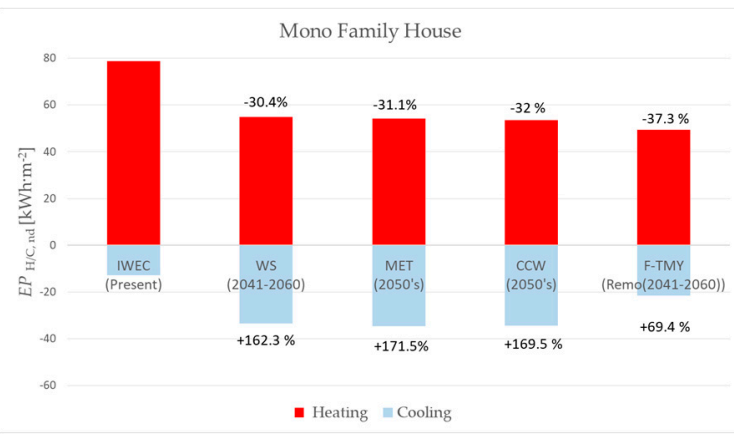

(a)

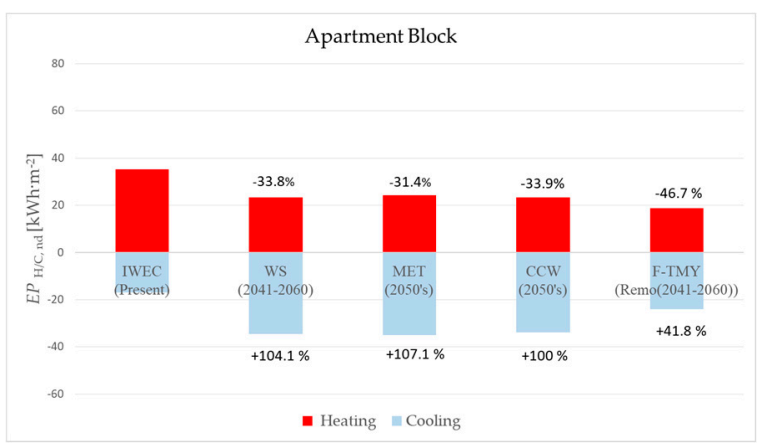

(b)

Figure 3. Net thermal energy needs for heating and cooling normalized by the conditioned floor area for a mono family house (a) and apartment block (b) for IWEC (Present), Weathershift (WS), Meteonorm (MET), CCWorldWeatehr-Gen (CCW), and F-TMY. All future weather files are for 2050s considering RCP 8.5.

In order to better present this trend, the box plots of thermal energy load for heating in the month of January and for cooling in the month of August are shown in Figures 4 and 5. The figures indicate that both for MFH and $A B$, the mean values for the month of January are almost the same for all future weather files, while the deviation of F-TMY is lower than the three other files. On the other hand, for the month of August, the mean values of WS, MET, and CCW are significantly higher than F-TMY. The reason lies in the fact that the dynamical downscaled weather data in comparison with the statistical ones better represents the temporal variability of climate, which leads to a more consistent dataset. As another outcome of the inconsistency in the statistical downscaled weather files, both figures demonstrate the overestimation of the data in the thermal energy load for cooling in August.

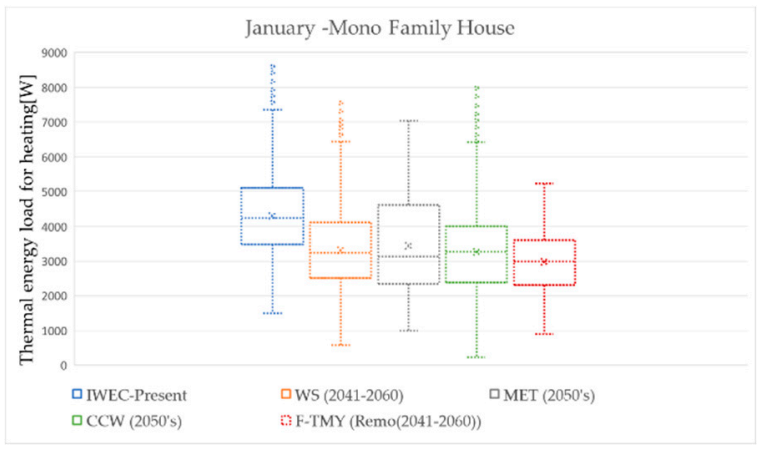

(a)

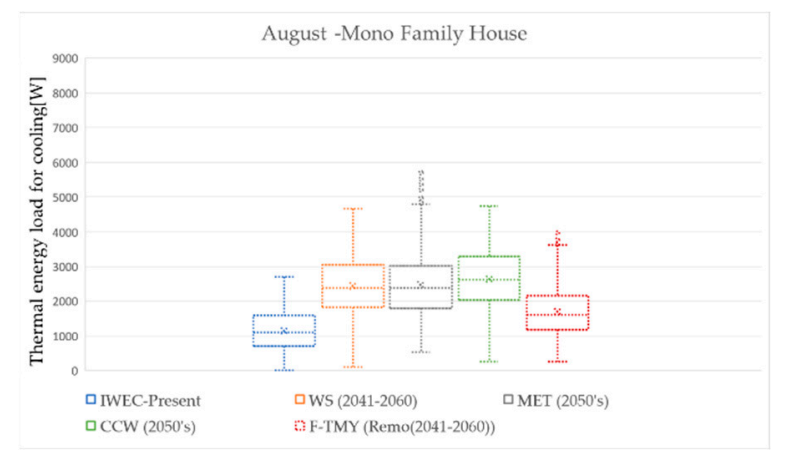

(b)

Figure 4. Boxplots of heating loads in January (a) and cooling loads in August (b) of the mono family house for IWEC (Present), Weathershift (WS), Meteonorm (MET), CCWorldWeatehr-Gen (CCW), and F-TMY. All future weather files are for 2050s considering RCP 8.5 .

The adaptive comfort analysis in free floating condition, of MFH and AB for IWEC (Present), Weathershift (WS), Meteonorm (MET), CCWorldWeatehrGen (CCW), and F-TMY is presented in Figure 6. The graphs show the distribution of hours of the cooling period (April 16th until October 14th: 4368 hours) in three ranges: comfort, warm discomfort, and cold discomfort. The discrepancy between F-TMY and other future weather data is pointed out. The percentage of warm discomfort hours for the WS, MET, and CCW is almost the same and equals around $40 \%$ for $\mathrm{MFH}$ and $90 \%$ for $\mathrm{AB}$. For the F-TMY, the percentage of warm discomfort hours is less for both cases (29\% for MFH and $72 \%$ for AB). This discrepancy can be found in Figure 7 where boxplots of last floor operative temperature of MFH (a) and AB (b) in August for present and different future weather data are presented. 
In this case, despite having similar dispersions, the mean values of last floor operative temperature of F-TMY is significantly lower than the mean value of the other three future weather datasets for both MFH and AB. This is strongly dependent on the lower dispersion of temperature values for F-TMY. If we now turn to the comparison of the two building types, occupants in $\mathrm{AB}$ will experience overheating much more often than the occupants in MFH because of a reduced potentiality of exploiting the heat transfer in $\mathrm{AB}$ through the envelope for ejecting heat produced by internal and solar sources. This is due to the lower S/V value and larger window-to-wall ratio (WWR) of the AB compared to MFH. In addition, hours of exceedance (HE) for all the weather datasets for MFH and $A B$ are presented in Table 1. It is observed that the absolute change of the increase in the HE for statistically downscaled future weather datasets is almost the same, while for dynamically downscaled future weather, data are significantly lower.

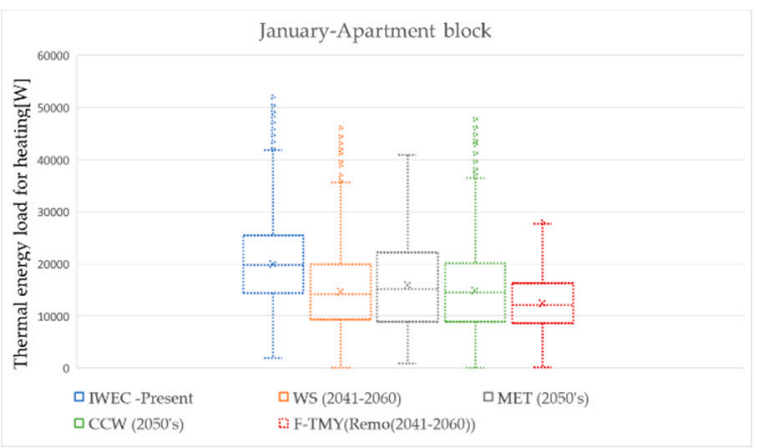

(a)

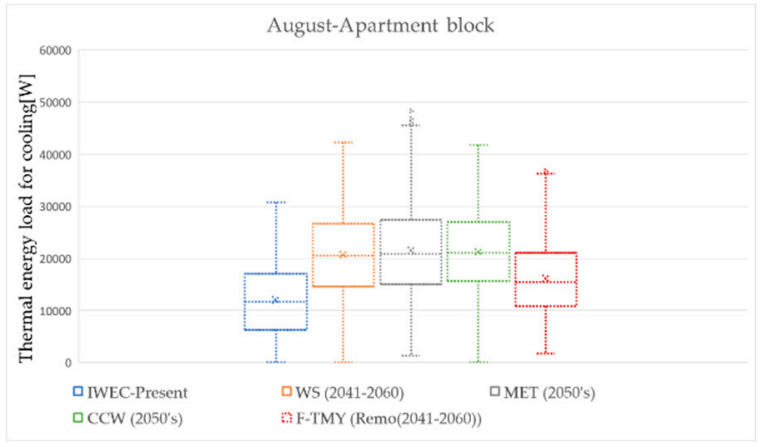

(b)

Figure 5. Boxplots of heating loads in January (a) and cooling load in August (b) of the apartment block for IWEC (Present), Weathershift (WS), Meteonorm (MET), CCWorldWeatehr-Gen (CCW), and F-TMY. All future weather files are for 2050s considering RCP 8.5 .

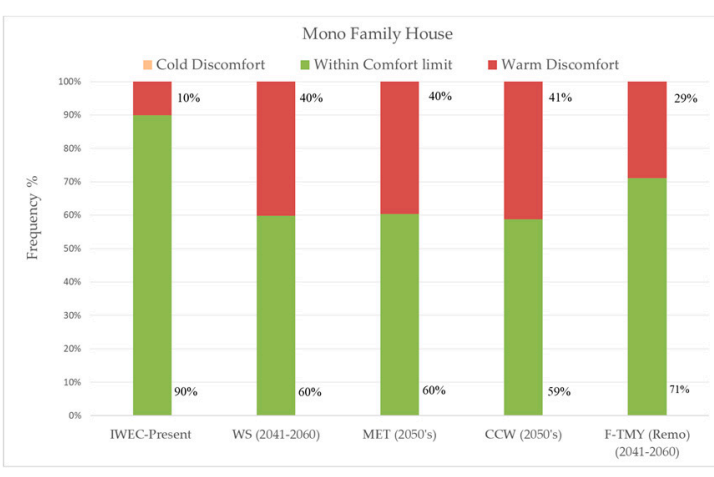

(a)

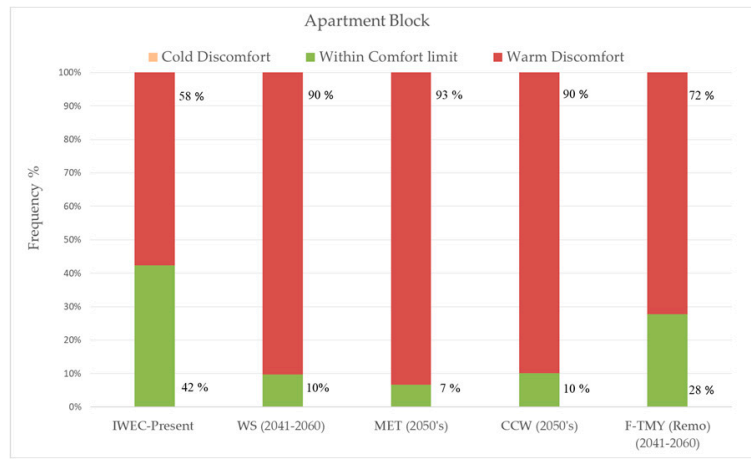

(b)

Figure 6. Adaptive comfort analysis for a mono family house (a) and apartment block (b) for IWEC (Present), Weathershift (WS), Meteonorm (MET), CCWorldWeatehr-Gen (CCW), and F-TMY. All future weather files are for 2050s considering RCP 8.5. 


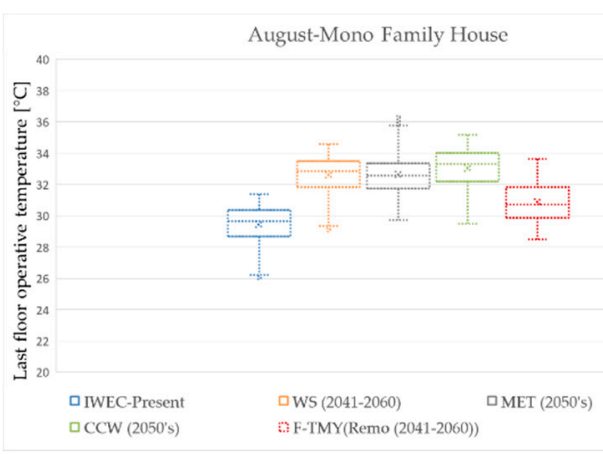

(a)

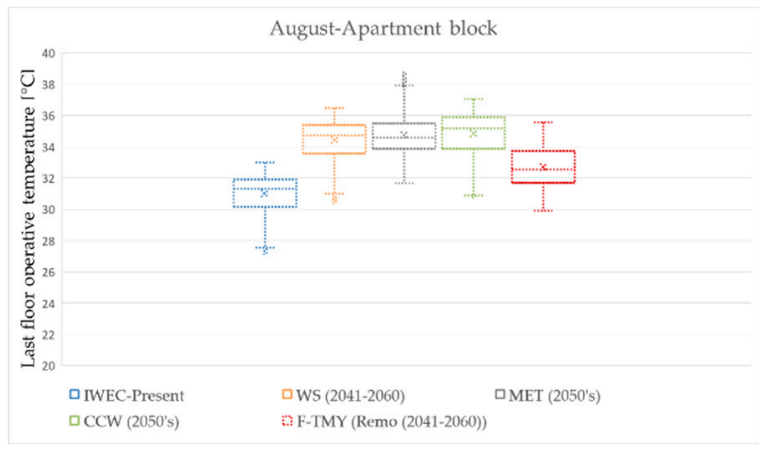

(b)

Figure 7. Boxplot of last floor operative temperature of a mono family house (a) and apartment block (b) in August, for IWEC (Present), Weathershift (WS), Meteonorm (MET), CCWorldWeatehr-Gen (CCW), and F-TMY. All future weather files are for 2050s considering RCP 8.5 .

Table 1. Electrical energy demand per unit of area and hours of exceedance for a mono family house (MFH) and apartment block (AB), for IWEC (Present), Weathershift (WS), Meteonorm (MET), CCWorldWeatehr-Gen (CCW), and F-TMY. All future weather files are for 2050s considering RCP 8.5.

\begin{tabular}{|c|c|c|c|c|c|c|c|c|c|c|}
\hline & & \multirow[b]{2}{*}{ IWEC } & \multicolumn{2}{|c|}{ WS } & \multicolumn{2}{|c|}{ MET } & \multicolumn{2}{|c|}{$\mathrm{CCW}$} & \multicolumn{2}{|c|}{ TMY-R } \\
\hline & & & & $\begin{array}{l}\text { Absolute } \\
\text { Change }\end{array}$ & & $\begin{array}{c}\text { Absolute } \\
\text { Change }\end{array}$ & & $\begin{array}{c}\text { Absolute } \\
\text { Change }\end{array}$ & & $\begin{array}{c}\text { Absolute } \\
\text { change }\end{array}$ \\
\hline \multirow{2}{*}{ SFH } & $\begin{array}{c}E_{\mathrm{el}} / A_{\mathrm{f}} \\
{\left[\mathrm{kWh} \mathrm{m}^{-2}\right]}\end{array}$ & 38.7 & 40.7 & 2 & 41.5 & 2.8 & 40.5 & 1.8 & 29.8 & -8.9 \\
\hline & $H E[\mathrm{~h}]$ & 222 & 887 & 665 & 877 & 655 & 910 & 688 & 638 & 416 \\
\hline \multirow{2}{*}{$\mathbf{A B}$} & $\begin{array}{c}E_{\mathrm{el}} / A_{\mathrm{f}} \\
{\left[\mathrm{kWh} \mathrm{m}^{-2}\right]}\end{array}$ & 22.9 & 29 & 6.1 & 29.5 & 6.6 & 28.1 & 5.2 & 19.4 & -3.5 \\
\hline & $H E[\mathrm{~h}]$ & 1273 & 1995 & 722 & 2060 & 787 & 1984 & 711 & 1596 & 323 \\
\hline
\end{tabular}

In addition, Table 1 also summarizes the values of the electrical energy demand per unit of area $\left(E_{\mathrm{el}} / A_{\mathrm{f}}\right)$. The $E_{\mathrm{el}} / A_{\mathrm{f}}$ increases in MFH and $\mathrm{AB}$ similarly for WS, MET, and $\mathrm{CCW}$, while the absolute change is not significantly high. On the other hand, $E_{\mathrm{el}} / A_{\mathrm{f}}$ slightly decreases for F-TMY in both cases. The reason can be explained below: as mentioned before, a future value for the mean seasonal efficiency of the heating $\left(\eta_{\mathrm{H}, \mathrm{g}}\right)$ and the cooling $\left(\eta_{C, \mathrm{~g}}\right)$ generation subsystem was adopted to consider the increase of ambient temperature due climate change. The mean seasonal efficiency increases for the heating and decreases for the cooling for all the future weather datasets. However, due to the lower discrepancy of the temperature values for F-TMY compared to other future weather datasets, the increase for $\eta_{\mathrm{H}, \mathrm{g}}$ in the dynamical downscaled model is more, while the decreases in the $\eta_{C, g}$ is less. Consequently, according to Equation (4), the reduction in the energy for winter conditioning outweighs the cooling demand in the case of F-TMY. Finally, if the variation of $E_{\mathrm{el}} / A_{\mathrm{f}}$ for $\mathrm{MFH}$ and $\mathrm{AB}$ are compared, the absolute changes are lower for $\mathrm{MFH}$, which comes from its higher $S / \mathrm{V}$ value that skews the energy usage of it more toward the heating regime.

\section{Conclusions}

Statistical and dynamical are two main approaches to downscale global climate models for creating weather datasets to be used in building energy simulation. Considering there are different methodologies that use these approaches, evaluating their suitability and robustness is vital. This study set out to compare WeatherShift, Meteonorm, and CCWorldWeatherGen-which are common weather generator tools applying statistical downscaling - in addition to a TMY created using a high-quality regional climate models 
database (from Euro-CORDEX) that applies the dynamical downscaling. All future weather files are for the 2050s considering RCP 8.5. Two representative buildings of the Italian residential building stock, including a mono family house (MFH) and an apartment block $(\mathrm{AB})$, were selected to perform the analysis.

The results of this investigation show that different statistical downscaled future weather datasets created by weather generators predict the future energy performance and comfort analysis of the buildings quite similarly, compared to the dynamical one. This is demonstrated by almost the same values in the mean outdoor dry-bulb temperature, relative changes of thermal energy need for heating and cooling normalized by the conditioned floor area, mean value of thermal energy load for heating and cooling, the hours of discomfort, and the absolute changes in the electrical energy demand per unit of area. However, when it comes to the dynamical downscaled weather data, the above-mentioned parameters follow a different pattern. As an example, while the discomfort hours percentage for the WS, MET, and CCW equals around $40 \%$ for MFH and $90 \%$ for $\mathrm{AB}$, for the F-TMY, this percentage is $29 \%$ for MFH and $72 \%$ for AB. Consequently, it was verified that dynamical downscaling, by better representing the spatial and temporal variability of local climate, provides physically consistent datasets.

The other significant result of this study is reached by comparing different building types. In more detail, the observed discrepancy between the future predictions of statistical and dynamical downscaling is affected not only by using different approaches for creating future weather datasets but also by building type. As an example, the thermal energy need for cooling in MFH for statistical downscaled datasets increases around $170 \%$, and for the dynamical one, it increases around $70 \%$. On the other hand, in $\mathrm{AB}$, this parameter increases $100 \%$ for statistical downscaled data and around $40 \%$ for the dynamical one. This inequality in relative variation comes from the different magnitude of the present energy need for different building types. For buildings with a higher shape factor (MFH), the heating energy demand dominates the cooling energy demand, which also make them more sensitive to the climate change.

Overall, this study has provided a deeper insight into analyzing the effect of climate change on the future energy performance of buildings by considering different future weather datasets and building types. Firstly, it was shown that the climate change impact magnitude is not equal for different case studies, so that in a changing climate, performing a regional and localized analysis becomes vital. In addition, the results demonstrated that morphing method - regardless of its way of application — can provide adequate information to perform comparative analysis on long-term changes in energy building performance. However, the existing inconsistency within this method may lead to high prediction errors. In this case, the dynamical downscaling method is found to be more reliable when the aim is to develop, assess, and communicate resilient solutions to withstand as well as prevent the future impacts of climate change on building energy performance. Further studies are suggested to be carried out to consider model uncertainties of RCMs by following an ensemble-based approach. In addition, it is important to bear in mind that RCMs have been run not only for future but also for historical period. So, they can be compared with the real data, and the biases associated with the climate model data can be adjusted to reduce uncertainties and increase their physical consistency. This possibility does not exist for statistical downscaling method tools, as they are based on transforming the actual real data; it is possible to say they are often "black-box" tools.

Author Contributions: Conceptualization, M.P. and V.C.; methodology, I.B., M.P, M.Z., and V.C.; software, M.P.; formal analysis, M.P.; investigation, M.P. and M.Z.; resources, M.P. and M.Z.; data curation, I.B. and M.P.; writing — original draft preparation, M.P.; writing—review and editing, I.B., M.Z., and V.C.; visualization, M.P.; supervision, V.C.; project administration, M.Z. and V.C. All authors have read and agreed to the published version of the manuscript.

Funding: This research received no external funding. 
Data Availability Statement: Publicly available datasets were analyzed in this study. These data can be found here: [https://energyplus.net/weather-location/europe_wmo_region_6/ITA//ITA_ Rome.162420_IWEC accessed on 2 December 2020] and [https:/ / esgf-node.llnl.gov/search/esgf-1lnl/ accessed on 2 December 2020].

Acknowledgments: The authors would like to thank Giovanni Murano for providing excel sheets that apply the methodology of standard EN ISO 15927-4 for generating typical meteorological year (TMY).

Conflicts of Interest: The authors declare no conflict of interest.

\section{References}

1. World Meteorological Organization. WMO Report on The Global Climate in 2015-2019; World Meteorological Organization: Geneva, Switzerland, 2019.

2. Symon, C. Climate change: Action, trends and implications for business. In The IPCC's Fifth Assessment Report, Working Group 1; IPCC: Geneva, Switzerland, 2013.

3. Della-Marta, P.M.; Haylock, M.R.; Luterbacher, J.; Wanner, H. Doubled length of western European summer heat waves since 1880. J. Geophys. Res. Space Phys. 2007, 112. [CrossRef]

4. National Climate Services Network of Italy, ISPRA. Future Climate in Italy—An Analysis of Regional Climate Models Projections; ISPRA: Roma, Italy, 2015; ISBN 978-88-448-0723-8.

5. Muthers, S.; Laschewski, G.; Matzarakis, A. The Summers 2003 and 2015 in South-West Germany: Heat Waves and Heat-Related Mortality in the Context of Climate Change. Atmosphere 2017, 8, 224. [CrossRef]

6. D’Ippoliti, D.; Michelozzi, P.; Marino, C.; De'Donato, F.; Menne, B.; Katsouyanni, K.; Kirchmayer, U.; Analitis, A.; Medina-Ramón, M.; Paldy, A.; et al. The impact of heat waves on mortality in 9 European cities: Results from the EuroHEAT project. Environ. Health 2010, 9, 37. [CrossRef] [PubMed]

7. Tan, J.; Zheng, Y.; Tang, X.; Guo, C.; Li, L.; Song, G.; Zhen, X.; Yuan, D.; Kalkstein, A.J.; Li, F.; et al. The urban heat island and its impact on heat waves and human health in Shanghai. Int. J. Biometeorol. 2009, 54, 75-84. [CrossRef] [PubMed]

8. Salimi, M.; Al-Ghamdi, S.G. Climate change impacts on critical urban infrastructure and urban resiliency strategies for the Middle East. Sustain. Cities Soc. 2020, 54, 101948. [CrossRef]

9. McEvoy, D.; Ahmed, I.; Mullett, J. The impact of the 2009 heat wave on Melbourne's critical infrastructure. Local Environ. 2012, 17, 783-796. [CrossRef]

10. Xia, Y.; Li, Y.; Guan, D.; Tinoco, D.M.; Xia, J.; Yan, Z.; Yang, J.; Liu, Q.; Huo, H. Assessment of the economic impacts of heat waves: A case study of Nanjing, China. J. Clean. Prod. 2018, 171, 811-819. [CrossRef]

11. Herbel, I.; Croitoru, A.-E.; Rus, A.V.; Roşca, C.F.; Harpa, G.V.; Ciupertea, A.-F.; Rus, I. The impact of heat waves on surface urban heat island and local economy in Cluj-Napoca city, Romania. Theor. Appl. Clim. 2018, 133, 681-695. [CrossRef]

12. Nakicenovic, N.; Alcamo, J.; Davis, G.; Vries, B.D.; Fenhann, J.; Gaffin, S.; Gregory, K.; Grubler, A.; Jung, T.Y.; Kram, T.; et al. Special Report on Emissions Scenarios; IPCC: Geneva, Switzerland, 2000.

13. Dimoudi, A.; Tompa, C. Energy and environmental indicators related to construction of office buildings. Resour. Conserv. Recycl. 2008, 53, 86-95. [CrossRef]

14. Shen, P. Impacts of climate change on U.S. building energy use by using downscaled hourly future weather data. Energy Build. 2017, 134, 61-70. [CrossRef]

15. Berardi, U.; Jafarpur, P. Assessing the impact of climate change on building heating and cooling energy demand in Canada. Renew. Sustain. Energy Rev. 2020, 121, 109681. [CrossRef]

16. Flores-Larsen, S.; Filippín, C.; Barea, G. Impact of climate change on energy use and bioclimatic design of residential buildings in the 21st century in Argentina. Energy Build. 2019, 184, 216-229. [CrossRef]

17. Soutullo, S.; Giancola, E.; Jiménez, M.J.; Ferrer, J.A.; Sánchez, M.N. How Climate Trends Impact on the Thermal Performance of a Typical Residential Building in Madrid. Energies 2020, 13, 237. [CrossRef]

18. Da Guarda, E.L.A.; Domingos, R.M.A.; Jorge, S.H.M.; Durante, L.C.; Sanches, J.C.M.; Leão, M.; Callejas, I.J.A. The influence of climate change on renewable energy systems designed to achieve zero energy buildings in the present: A case study in the Brazilian Savannah. Sustain. Cities Soc. 2020, 52, 101843. [CrossRef]

19. Zhai, Z.J.; Helman, J.M. Implications of climate changes to building energy and design. Sustain. Cities Soc. 2019, 44, 511-519. [CrossRef]

20. Chai, J.; Huang, P.; Sun, Y. Investigations of climate change impacts on net-zero energy building lifecycle performance in typical Chinese climate regions. Energy 2019, 185, 176-189. [CrossRef]

21. Herrera, M.; Natarajan, S.; Coley, D.A.; Kershaw, T.; Ramallo-González, A.P.; Eames, M.; Fosas, D.; Wood, M. A review of current and future weather data for building simulation. Build. Serv. Eng. Res. Technol. 2017, 38, 602-627. [CrossRef]

22. Hall, I.J.; Prairie, R.R.; Anderson, H.E.; Boes, E.C. Generation of a Typical Meteorological Year (No. SAND-78-1096C; CONF-780639-1); Sandia Labs: Albuquerque, NM, USA, 1978.

23. Barnaby, C.S.; Crawley, D.B. Weather data for building performance simulation. In Building Performance Simulation for Design and Operation; Routledge: London, UK, 2011.

24. Finkelstein, J.M.; Schafer, R.E. Improved goodness-of-fit tests. Biometrika 1971, 58, 641-645. [CrossRef] 
25. Jentsch, M.F.; James, P.A.; Bourikas, L.; Bahaj, A.S. Transforming existing weather data for worldwide locations to enable energy and building performance simulation under future climates. Renew. Energy 2013, 55, 514-524. [CrossRef]

26. Dias, J.B.; Da Graça, G.C.; Soares, P.M. Comparison of methodologies for generation of future weather data for building thermal energy simulation. Energy Build. 2020, 206, 109556. [CrossRef]

27. Moazami, A.; Nik, V.M.; Carlucci, S.; Geving, S. Impacts of future weather data typology on building energy performanceInvestigating long-term patterns of climate change and extreme weather conditions. Appl. Energy 2019, 238, 696-720. [CrossRef]

28. U.S. Department of Energy's (DOE). Energy Plus Software, v. 9.0. Available online: https://energyplus.net/ (accessed on 2 September 2020).

29. Köppen, W. Die Wärmezonen der Erde, nach der Dauer der heissen, gemässigten und kalten Zeit und nach der Wirkung der Wärme auf die organische Welt betrachtet. Meteoro. Z. 1884, 1, 5-226.

30. Hawkins, E.; Sutton, R.T. The Potential to Narrow Uncertainty in Regional Climate Predictions. Bull. Am. Meteorol. Soc. 2009, 90, 1095-1108. [CrossRef]

31. Hawkins, E.; Sutton, R. The potential to narrow uncertainty in projections of regional precipitation change. Clim. Dyn. 2011, 37, 407-418. [CrossRef]

32. Ramon, D.; Allacker, K.; Van Lipzig, N.P.M.; De Troyer, F.; Wouters, H. Future Weather Data for Dynamic Building Energy Simulations: Overview of Available Data and Presentation of Newly Derived Data for Belgium. Energy Environ. Sustain. 2018, 111-138. [CrossRef]

33. Uppala, S.M.; Kållberg, P.W.; Simmons, A.J.; Andrae, U.; Bechtold, V.D.C.; Fiorino, M.; Gibson, J.K.; Haseler, J.; Hernandez, A.; Kelly, G.A.; et al. The ERA-40 re-analysis. Q. J. R. Meteorol. Soc. 2005, 131, 2961-3012. [CrossRef]

34. Laflamme, E.M.; Linder, E.; Pan, Y. Statistical downscaling of regional climate model output to achieve projections of pre-cipitation extremes. Weather. Clim. Extrem. 2016, 12, 15-23. [CrossRef]

35. Belcher, S.; Hacker, J.; Powell, D. Constructing design weather data for future climates. Build. Serv. Eng. Res. Technol. 2005, 26, 49-61. [CrossRef]

36. American Meteorological Society. Regional climate model. In Glossary of Meteorology; American Meteorological Society: Boston, MA, USA, 2013.

37. Soares, P.M.; Cardoso, R.M.; Miranda, P.M.; de Medeiros, J.; Belo-Pereira, M.; Espirito-Santo, F. WRF high resolution dynam-ical downscaling of ERA-Interim for Portugal. Clim. Dyn. 2012, 39, 2497-2522. [CrossRef]

38. Van der Linden, P.; Mitchell, J.E. ENSEMBLES: Climate Change and its Impacts: Summary of Research and Results from the ENSEMBLES Project; Met Office Hadley Centre: Exeter, UK, 2009.

39. Jacob, D.; Petersen, J.; Eggert, B.; Alias, A.; Christensen, O.B.; Bouwer, L.M.; Braun, A.; Colette, A.; Déqué, M.; Georgievski, G.; et al. EURO-CORDEX: New high-resolution climate change projections for European impact research. Reg. Environ. Chang. 2014, 14, 563-578. [CrossRef]

40. Giorgi, F. Thirty Years of Regional Climate Modeling: Where Are We and Where Are We Going next? J. Geophys. Res. Atmos. 2019, 124, 5696-5723. [CrossRef]

41. World Research Climate Program (WRCP) Coordinated Downscaling Experiment-European Domain. Available online: https: / / www.eurocordex.net/ (accessed on 2 December 2020).

42. EUROCORDEX: Cordex Archive Specifications. Available online: https://is-enes-data.github.io/cordex_archive_specifications pdf (accessed on 2 December 2020).

43. Jacob, D.; Podzun, R. Sensitivity studies with the regional climate model REMO. Theor. Appl. Clim. 1997, 63, 119-129. [CrossRef]

44. Jacob, D. A note to the simulation of the annual and inter-annual variability of the water budget over the Baltic Sea drain-age basin. Meteorol. Atmos. Phys. 2001, 77, 61-73. [CrossRef]

45. Remund, J.; Kunz, S. METEONORM: Global Meteorological Database for Solar Energy and Applied Climatology; Meteotest: Bern, Switzerland, 1997.

46. Climate Change 2007: Synthesis Report. Contribution of Working Groups I, II and III to the Fourth Assessment Report of the Intergovernmental Panel on Climate Change. In Intergovernmental Panel on Climate Change; Core Writing Team, Pachauri, R.K., Resinger, A., Eds.; IPCC: Geneva, Switzerland, 2007.

47. Remund, J.; Müller, S.C.; Schilter, C.; Rihm, B. The use of Meteonorm weather generator for climate change studies. In Proceedings of the10th EMS Annual Meeting 2010, Zürich, Switzerland, 13-17 September 2010. EMS2010-417.

48. Met Office HadCM3: Met Office Climate Prediction Model. Available online: https://www.metoffice.gov.uk/research/approach/ modelling-systems/unified-model/climate-models/hadcm3 (accessed on 2 December 2020).

49. Jentsch, M.F. Technical Reference Manual for the CCWeatherGen and CCWorldWeatherGen Tools Version 1.2. 2012. Available online: http://blog.soton.ac.uk/serg/files/2013/06/manual_weather_tool1.pdf (accessed on 2 December 2020).

50. Jentsch, M.F.; Bahaj, A.S.; James, P.A. Climate change future proofing of buildings-Generation and assessment of building simulation weather files. Energy Build. 2008, 40, 2148-2168. [CrossRef]

51. WeatherShift. Available online: http:/ / www.weather-shift.com (accessed on 2 December 2020).

52. Pachauri, R.K.; Reisinger, A. Climate Change 2007. Synthesis Report. Contribution of Working Groups I, II and III to the fourth Assessment Report; IPCC: Geneva, Switzerland, 2008.

53. Troup, L.; Fannon, D. Morphing Climate Data to Simulate Building Energy Consumption. In Proceedings of the ASHRAE and IBPSA-USA SimBuild 2016: Building Performance Modeling Conference, Salt Lake City, UT, USA, 12-10 August 2016; Volume 6. 
54. CORDEX Data Extractor. Available online: https://agrimetsoft.com/CordexDataExtractor (accessed on 2 December 2020).

55. Flato, G.; Marotzke, J.; Abiodun, B.; Braconnot, P.; Chou, S.C.; Collins, W.; Cox, P.; Driouech, F.; Emori, S.; Eyring, V.; et al. Evaluation of climate models. In Climate Change 2013: The Physical Science Basis. Contribution of Working Group I to the Fifth Assessment Report of the Intergovernmental Panel on Climate Change; Cambridge University Press: Cambridge, UK, $2014 ;$ pp. 741-866.

56. European Committee for Standardization. EN ISO 15927-4. Hygrothermal Performance of Buildings Calculation and Presentation of Climatic Data, Part 4: Hourly Data for Assessing the Annual Energy Use for Heating and Cooling; European Committee for Standardization: Brussels, Belgium, 2005.

57. O. J. of the Italian Republic. Italian Republic, Interministerial Decree of June 26th, 2015-Calculation Methodologies of the Building Energy Performance and Minimum Energy Performance Requirements (in Italian); O. J. of the Italian Republic: Rome, Italy, 2015.

58. European Committee for Standardization. EN ISO 16798-1. Energy Performance of Buildings-Ventilation for Buildings-Part 1: Indoor Environmental Input Parameters for Design and Assessment of Energy Performance of Buildings Addressing Indoor Air Quality, Thermal Environment, Lighting, and Acoustics-Module M1-6; European Committee for Standardization: Brussels, Belgium, 2019.

59. Ballarini, I.; Corgnati, S.P.; Corrado, V. Use of reference buildings to assess the energy saving potentials of the residential building stock: The experience of TABULA project. Energy Policy 2014, 68, 273-284. [CrossRef]

60. Comitato Termotecnico Italiano. Technical Commission 241, doc. no. 181, Italian National Annex of the EN 16798-1 Technical Standard (Working Draft for Internal Use); Comitato Termotecnico Italiano: Milan, Italy, 2020. 